\title{
Clinical practice in medical genetics
}

\section{Recommendations for Education and Training of Genetic Nurses and Counsellors in the United Kingdom}

\author{
H Skirton, C Barnes, P Guilbert, A Kershaw, L Kerzin-Storrar, C Patch, G Curtis, \\ $\mathrm{J}$ Walford-Moore
}

Clinical Genetics,

Taunton and Somerset

NHS Trust, Musgrove

Park, Taunton,

Somerset TA1 5DA,

UK

H Skirton

South Thames

Regional Genetics

Centre (East), London,

UK

C Barnes

Department of Clinical Genetics, Nottingham, UK

P Guilbert

East Anglian Regional Genetic Services, UK

A Kershaw

Department of Medical Genetics,

Manchester, UK

L Kerzin-Storrar

Wessex Clinical Genetics Service, UK

C Patch

G Curtis

West Midlands

Regional Genetics

Service, UK

J Walford-Moore

Correspondence to: Mrs Skirton.

Received 25 September 1997 Revised version accepted for publication

28 November 1997

\begin{abstract}
Genetic nurses and counsellors work as part of the professional team providing clinical genetic services from regional centres in the United Kingdom. The education and training needs of genetic nurses and counsellors have not previously been formally identified. The guidelines presented have been devised to equip practitioners to fulfil their professional role as defined in a previous study, by identifying objectives, educational pathways, and means of assessment. While academic courses provide an essential framework, experiential learning in a clinical setting is also considered a vital component of the preparation for practice.

( $\mathcal{}$ Med Genet 1998;35:410-412)
\end{abstract}

Keywords: genetic nurses; counsellors; recommendations, education, and training

Within the United Kingdom, clinical genetic services are provided by regional units as part of the National Health Service. The professional team providing the service generally consists of consultant doctors in clinical genetics, genetic nurses/counsellors, doctors training in genetics, and administration staff. Each unit may operate differently according to historical background, managerial style, and composition of the team. During 1994, discussion about the developing role of genetic nurses prompted the Association of Genetic Nurses and Counsellors (AGNC) in the United Kingdom (UK) to convene a working party to investigate the practice and role of genetic nurses and counsellors. ${ }^{1}$

The report on the role and practice of genetic nurses and counsellors indicated that there was sufficient common ground between individual centres and practitioners to devise a set of training and educational guidelines. The decision to produce educational guidelines coincided with the initiatives by the United Kingdom Central Council (UKCC), the statutory regulatory body for nursing practice within the UK, to formalise requirements for specialist nurse practice in all areas of health care. In addition, the establishment of a Master of Science (MSc) course in genetic counselling has provided an alternative pathway to practice. There have been no statutory or generally recognised training requirements for specialist genetic nurses/counsellors; therefore each practitioner has received training dependent upon individual interest and motivation, and the resources and interest of the managers responsible. Both clinical genetics and nursing have altered enormously over the past decade, and this ad hoc approach to professional training is inadequate. In North America, genetic counsellors have developed a formal accreditation process using practice based competencies. ${ }^{2}$

Based on the previous study, the training and education of genetic nurses and counsellors must equip the practitioner to undertake the following aspects of practice.

\section{Direct client contact}

Preclinic contact to take a history and pedigree, give general information about the condition and the genetic service, and elicit the client's concerns.

Clinic consultation in conjunction with a doctor.

Nurse/counsellor consultation to give information, arrange tests, give results, arrange family studies.

Postclinic contact to reinforce information, provide support during decision making, or provide continuing contact as appropriate.

Client counselling, particularly at times of crisis, decision making, or after a new diagnosis has been made.

\section{Education}

Provision of education and training for colleagues in the health and social services.

\section{Research}

Initiation of research.

Collaboration with research led by colleagues.

Assessment and use of research findings for good practice. 
Table 1 Core recommendations for the education of genetic nurses and counsellors

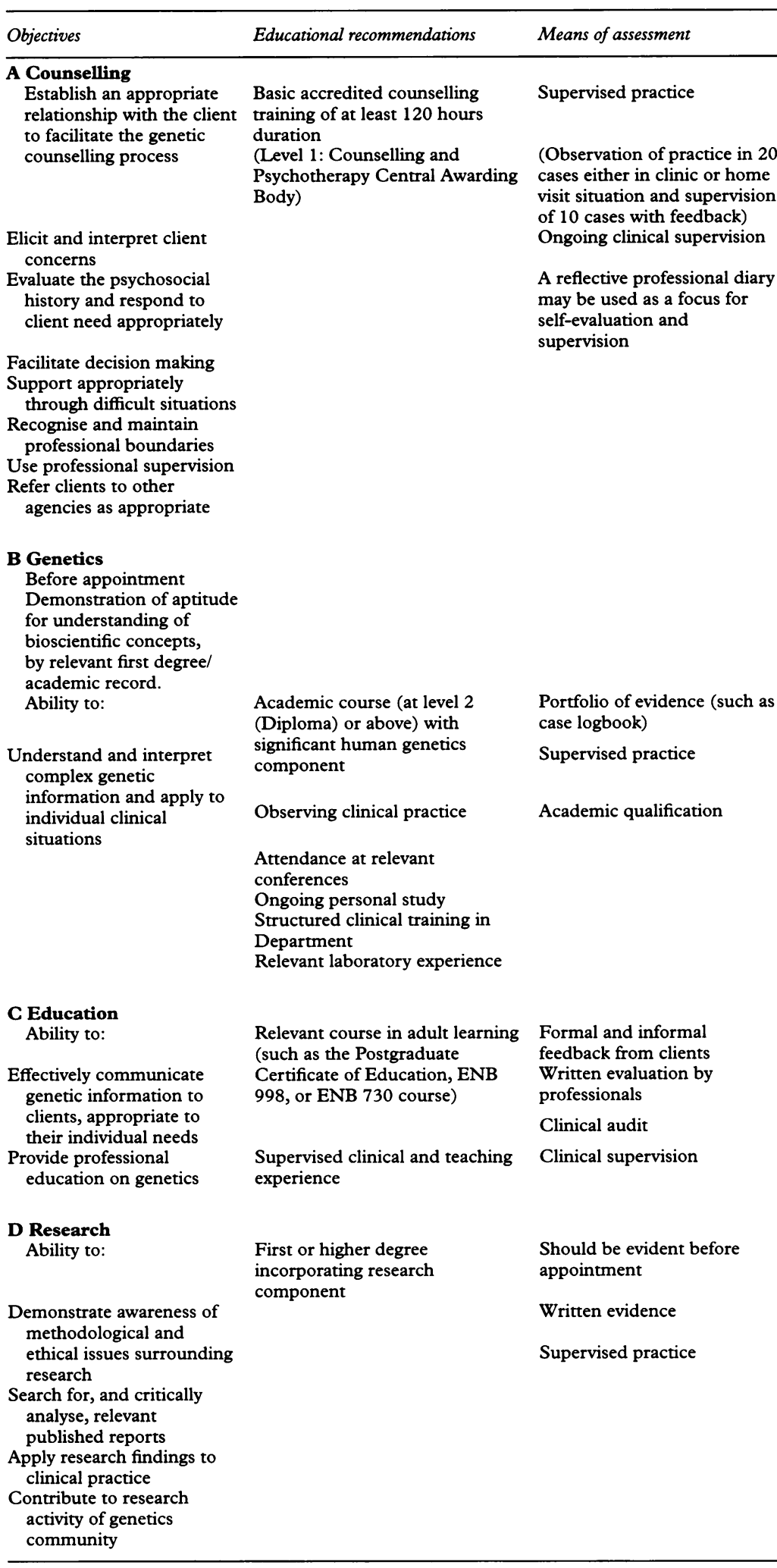

Psychotherapeutic counselling

Psychotherapeutic counselling for issues related to the genetic condition in the family offered by some centres.

\section{Administration}

Administrative and managerial tasks in the department.

The prepared guidelines have been based on the findings of the AGNC study on nursing practice, which included the opinions of medi- cal colleagues in clinical genetics, as well as current publications on specialist nurse practice and guidance from the statutory body governing the profession. After preparation of a draft by the AGNC Working Party on Education and Training, the opinion of members of the AGNC was sought, by means of an open workshop. Following revision, the draft was circulated to all members for further opinion before the final document was produced. This is, therefore, a document which represents the views of the entire membership of the AGNC. Recognising the differences in style between regional departments, the guidelines are not intended to be prescriptive, but to offer a pathway for professional development. They emphasise the core competencies considered essential for practice and acknowledge that these may be achieved by different educational pathways. The guidelines (table 1) consist of (1) specific knowledge or skill requirements; (2) the educational or training path recommended to achieve them; and (3) an appropriate means of assessment.

The study findings clearly indicated that genetic nurses fulfil the criteria defining specialist nursing practice published by the Royal College of Nursing ${ }^{3}$ (RCN) and reviewed more recently by the UKCC. ${ }^{4}$ According to the $\mathrm{RCN}$, specialist nursing practice includes expert clinical practice, consultation, teaching, management, and research, the preparation for which must include both a graduate education and extensive experience. While higher education may equip the nurse with a scientific knowledge base and critical thinking skills, experiential learning will assist the development of the professional competency described by Benner ${ }^{5}$ as know-how. Benner is convinced that while academic education provides the necessary theoretical underpinning to practice, the higher skills can only be obtained through extensive practical experience within the field. Observation of good practice by other skilled practitioners, and reflection on personal practice is part of the experiential process. Humphris ${ }^{6}$ considers that the specialist role is one which enables the humanitarian concerns of patients to be considered "in the face of increasing technology", an issue of exceptional relevance in the field of clinical genetics. Schon ${ }^{7}$ divides clinical practice into two distinct zones, the technical aspects of care, and the more nebulous areas of human response and interaction. The genetic nurse/counsellor needs to be able to operate effectively in both spheres, to understand and explain the complex genetic information, and to deal sensitively and appropriately with the human response. The psychosocial issues can only be adequately addressed if training has included supervised clinical experience over a sufficient period of time, and where feedback and reflection is sought and given. The team structure in clinical genetics lends itself to the use of mentors, which facilitates this process.

At present, there are a number of practitioners in clinical genetics who will have achieved the necessary skill and knowledge to practice 
by means of many years of clinical experience, and their expertise is acknowledged. While these recommendations define a foundation level of skill commensurate with safe practice, it should be recognised that some practitioners have expertise, knowledge, and responsibility which advances the boundaries of practice. Consideration needs to be given to the development of an appropriate career structure in this speciality. The AGNC endorses the increasing emphasis on professional accountability of all practitioners. Genetic nurses and counsellors have both a right and a responsibility to ensure that their educational preparation is appropriate to enable them to deliver an excellent standard of patient care. ${ }^{489}$ Discussion and comment from our clinical colleagues is invited.
1 Skirton H, Barnes C, Curtis G, Walford-Moore J. The role and practice of the genetic nurse: report of the AGNC Working Party. ₹ Med Genet 1997;34:141-7.

2 Fine B, Baker D, Fiddler M, and ABGC Consensus DevelFine B, Baker D, Fiddler M, and ABGC Consensus Devel-
opment Consortium. Practice based competencies for accreditation of and training in graduate programs in genetic counseling. $f$ Genet Couns 1996;5:113-21.

3 Royal College of Nursing. Specialities in nursing. London: Royal College of Nursing, 1988.

4 United Kingdom Central Council for Nursing, Midwifery and Health Visiting. The future of professional practice - the Council's standards for education and practice following registration. London: UKCC, 1994.

5 Benner P. From novice to expert. New York: Addison-Wesley, 1984.

Humphris D. The clinical nurse specialist. Chapter 1. Basingstoke: Macmillan Press, 1994.

7 Schon DA. Educating the reflective practitioner. San Francisco: Josey-Bass, 1987.

8 United Kingdom Central Council for Nursing, Midwifery and Health Visiting. Code of professional conduct. London: UKCC, 1992.

9 United Kingdom Central Council for Nursing, Midwifery and Health Visiting. Scope of professional practice. London: UKCC, 1992. 